Хренов Н.А.

\title{
Пределы эскалации коммуникативных технологий: ностальгия по площади. Продолжение
}

\begin{abstract}
Аннотация: В статье освещается вопрос о взаимоотношениях культуры и циивлизации,
\end{abstract} рассматриваемых сквозь призму развертывания коммуникативнъх процессов в истории. Острота этой проблемы осознается особенно в связи с функционированием во второй половине ХХ века телевидения, а в последние десятилетия интернета. Однако в это время лишь осознается то, что в реальной практике коммуникации существует со времен появления письменности. История массовой коммуникации связана с последовательнъц включением в культуру разных технологий, нередко выводящих коммуникативные процессы за предель культуры. Технологии репрезентируют, прежде всего, установки цииилизации. Однако другой своей стороной массовая коммуникация обращена к культуре, которая в соответствии с утверждением И. Хейзинаи, “рождается именно в личности и, следовательно, именно в личности сохраняет свое здоровъе». Это несовпадение установок цуивилизции и культуры в постановке проблемы личностного потенциала массовой коммуникации является, в конечном счете, решаюшим. Там, где массовая коммуникация выражает установки цзивилизации, личность в коммуникативном процессе предстает объектом. Цивилизация заинтересована в расширении коммуникативного пространства и, следовательно, в подключении к коммуникации как можно большего количества людей. Массовая коммуникация призвана разрешать те проблемы, которые в истории цзивилизации появляются в связи с возникновением массовых обществ и процессами омассовления культуры. Субъектом коммуникативных процессов личность предстает лишь в том случае, если технологии не выводят коммуникацию за предель культуры, как это нередко происходит и о чем свидетельствует практика медиа, в том числе, кино, телевидения и интерната, а соотносятся с ее установками. Однако чтобы привести технологии в соответствие с установками культуры, необходимо время. Иногда критических оценок функционирования средств коммуникации, возникающих на основе мощных технологий, приходится ждать долго. До этого человечество нередко пребывает в эйфории от технических возможностей коммуникации. Такая постановка вопроса делает необходимым развертывание исторических исследований коммуникации, но отнюдь не в апологетическом понимании, как это нередко происходит.

Review: The author of the article touches upon the issue about the relation between culture and civilization that are being viewed in terms of development of communication processes throughout history. The importance of this problem is especially recognized due to the appearance of TV broadcast at the second half of the $X X^{\text {th }}$ century and the Internet over the last decade. However, the only provision being actually recognized is that in actual practice communication has been existing since the times of appearance of the written language. The history of mass communication relates to the successive involvement of different technologies in the cultural process. Quite often these technologies take communication processes beyond the borders of culture. Technology represents civilization preferences. However, the other side of mass communication addresses culture which, in accordance with Johan Huizinga's statement, is born in personality and therefore retains its health in personality'. This discordance between preferences of civilization and culture plays the decisive role in raising the problem about personal potential of mass communication. Where mass communication expresses preferences of civilization, personality plays the role of an object in the communication process. Civilization tends to expand the communication space and therefore to involve as many people as possible into the communication process. Mass communication is meant to solve the problems that usually arise in the history of civilization when mass societies appear and processes of massification of culture are started. Personality becomes an actor of communication processes only when technology answers the preferences of culture but does not take communication beyond the borders of culture as it often happens and what mass media such as cinematograph, TV broadcast and the Internet often demonstrates. Sometimes it takes too long for the critical evaluation of the new communication media created on the basis of advanced technologies to be formed. So the humanity is often too excited about the opportunities that the new mean of communication may offer. Such statement of the question makes it necessary to undertake further historical researches of communication but not in the apologetic meaning as it often happens. 
Ключевъе слова: глобализация, индивидуализация, омассовление, массовая коммуникация, массмедиа, цивилизация, культура, книгопечатание, письменность, кинематограф.

Keywords: globalization, individualization, massification, civilization, mass communication, mass media, book printing, culture, written language, cinematograph.

Часть вторая

\section{8. Генезис мозаичности: расщепление печатной культуры на литературу и прессу.}

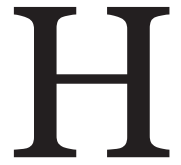

есмотря на столь мощное воздействие печатной книги на культуру и на структуры индивидуальной идентичности, все же уже собственно в самом этом средстве возникло нечто такое, что затем будет подхвачено и развито последующими средствами коммуникации - телевидением и интернетом. Ведь Гутенберг вызвал к жизни не только книгу, но и газету. Казалось бы, и книга, и газета демонстрируют нечто однородное, но, тем не менее, их разделяют рецептивные признаки. Если книга ориентирована на индивидуальное, то газета на коллективное восприятие.

Именно эту особенность подчеркивает М. Маклюен, обращая внимание на то, что мозаичные структуры рождаются как раз на газетной полосе и являются книге чуждыми. «Ведь популярная пресса не предлагает, - пишет он, - ни индивидуального взгляда, ни точки зрения, а предлагает лишь мозаику позиций коллективного сознания, о чем говорил Малларме. Однако эти формы коллективного, или племенного, сознания, множащиеся в телеграфной (симультанной) прессе, остаются чужими и непонятными книжному человеку, скованному «ньютоновским сном» и рамками индивидуального видения» ${ }^{1}$.

Будучи вызванными к жизни еще в недрах печатной культуры, эти мозаичные структуры сначала достигают своего пика развития в собственно печатной культуре, а затем, уже в XX веке они выходят за пределы этой культуры и определяют развитие аудиовизуальных средств коммуникации. М. Маключен констатирует эту преемственность. Он пишет: «Этот мозаичный телевизионный образ уже был в общих чертах

\footnotetext{
${ }^{1}$ Маклюен М. Галактика Гутенберга. Сотворение человека печатной культуры. С. 389;
}

намечен в популярной прессе, выросшей вместе с телеграфом» ${ }^{2}$.

Может быть, развитие мозаичных структур быстрее всего осуществилось в Америке, что не удивительно, поскольку здесь существовали этому способствующие специфические условия. Этому способствовали, прежде всего, успехи демократии. Помимо многих позитивных признаков этой политической системы можно отметить ряд других признаков, которые никак нельзя назвать позитивными. В частности, именно здесь имеет место явление, которое в других культурах развертывается незаметно и в больших длительностях времени, а именно, вытеснение книги газетой. Это весьма противоречивое явление, впервые в гипертрофированном виде ставшее возможным в стране победившей демократии, было прокомментировано А. де Токвилем, отметившим в середине XIX века, что, в сущности, американцы еще не имеют собственной литературы, ее повсеместно заменяет журналистика. «Единственные авторы, - пишет он, - которых я считаю настоящими американцами, это журналисты. Они обладают скромным литературным дарованием, но они говорят на языке своей страны, и их слышат. Все остальные литераторы мне кажутся здесь чужеземными» ${ }^{3}$.

Однако какие последствия возникают в том случае, когда журналистика начинает вытеснять литературу? К ним относится то, что если книга привлекает читателя погружением в индивидуальные ценности, то газета, по сути дела, является тем, на что проецируются коллективные настроения и представления, исключающие все, что связано с индивидуальностью автора и авторской точкой зрения. «Литература демократических веков, взятая в целом, в отличие от литературы аристократических времен, - пишет А. де Токвиль, - не сможет создать о себе впечатление упорядо-

\footnotetext{
${ }^{2}$ Маклюен М. Понимание медиа: внешние расширения человека., с. 371 ;

3 Токвиль де А. Демократия в Америке. М., 1992., c. 348 ;
} 
ченности, правильности, учености и высокого мастерства; ее форма обычно будет носить следы небрежности, а подчас и небрежения. Ее слог часто будет странным, неправильным, перегруженным или вялым и почти всегда дерзким и пылким. Авторы будут больше заботится о том, что бы работа выполнялась быстро, чем о совершенстве деталей. Коротких произведений станет больше, чем толстых книг, остроумие будет встречаться чаще, чем эрудиция, а оригинальное воображение - чаще глубокого мышления; в сфере мысли будет господствовать непросвещенная и почти дикая напористость, часто воплощающаяся в чрезмерном разнообразии и чрезвычайной плодовитости. Писатели будут стараться не столько нравиться, сколько изумлять, изо всех сил пытаясь завладеть чувствами читателя, не обращая особого внимания на его вкус» 4 .

То, что газета оказывается беспомощной в плане изложения и внедрения в массовое сознание определенной авторской позиции, отмечал еще Н. Данилевский. Так, ссылаясь на английскую газету «Times», которая имела наибольшее общественное влияние, Н. Данилевский утверждает: «Но именно она и не проповедует никаких своих мнений, а старается только искусно изложить те, которые господствуют в английском обществе о том или другом вопросе, подметить английские общественные интересы, уяснить их и, таким образом, возвести на степень общественной силы» 5 .

Связанные с вытеснением литературы журналистикой метаморфозы в других странах развертываются в более медленных ритмах. К такой стране, например, относится Россия. Хотя этот процесс бурного развития журналистики в России развертывается на протяжении всего XIX века, тем не менее, он все же не заглушает ренессанса русской литературы и, в частности, психологического романа. Хотя многие из писателей (в том числе, Пушкин, Некрасов. Достоевский и другие) активно занимаются издательским делом, выступая в периодической печати, журналистика все же не упраздняет самостоятельности литературы. Однако уже на рубеже XIX-XX веков противоречие достигает пика. В 20-е годы некоторые это противоречие пытаются оценивать позитивно. Так, С. Третьяков писал: «Наш эпос - газета. Подсчитаем сравнительно тираж газет и так называемой

\footnotetext{
${ }^{4}$ Токвиль де А. Указ. соч.. с. 351;

${ }^{5}$ Данилевский Н. Указ. соч., с. 284;
}

«изящной» литературы во времена Толстого и сейчас - и нам ясно станет, что газетная гора задавила беллетристику. Недаром же все писатели без исключения нырнули в газеты, и только некоторая газетная косность допускает, что они сохраняют облик беллетристов на страницах газет. То, чем была библия для средневекового христианства - указателем на все случаи жизни, то, чем был для русской либеральной интеллигенции учительный роман, - тем в наши дни для советского активиста является газета... Основная наша задача - не ждать красных эпиков. А приучать всю советскую аудиторию читать газету, эту библию сегодняшнего дня» ${ }^{6}$.

Однако далеко не все размышляющие о возникшем противоречии придерживались столь оптимистического взгляда. Так, в 1928 году О. Мандельштам печатает статью «Конец романа», в которой поэт пытается понять судьбу литературы в той ее форме, что успела сформироваться к XX веку. Как утверждает поэт, вплоть до последних дней роман был определяющей насущной необходимостью и организованной формой европейского искусства. Романы XIX века были столько же художественными событиями, сколько и событиями общественной жизни. Однако история романа оказывается тесно связанной с судьбой личности в истории. Расцвет романа стал следствием повышения статуса личности в культуре. Однако в ХХ веке ситуация изменяется, и акции личности в истории падают. Если основой романа XIX века была биография человека, то XX век демонстрирует «распыление биографии», даже «катастрофическую гибель биографии». «Ныне - пишет О. Мандельштам, - европейцы выброшены из своих биографий, как шары из биллиардных луз, и законами их деятельности, как столкновением шаров на биллиардном поле, управляет один принцип: угол падения равен углу отражения. Человек без биографии не может быть тематическим стержнем романа, и роман, с другой стороны, немыслим без интереса к отдельной человеческой судьбе, - фабуле и всему, что ей сопутствует. Кроме того, интерес к психологической мотивировке, куда так искусно спасался упадочный роман, уже предчувствуя свою погибель, - в корне подорван и дискредитирован наступившим бессилием психологических мотивов перед реальными силами, чья расправа с психоло-

${ }^{6}$ Третьяков С. Новый Лев Толстой. Новый Леф., 1927., №1., c. 36; 
гической мотивировкой час от часу становится более жестокой» ${ }^{7}$.

Таким образом, «смерть романа», а точнее, то противоречие, что связано с новыми взаимоотношениями между литературой и журналистикой в эпоху печатной культуры, во многом подготовили почву для последующего становления мозаичных форм повествования, но уже не в формах собственно печатной культуры, а в формах визуальной культуры. Конечно, какие-то структурные механизмы печати остаются реальными и для кинематографа. Их наличие не может не констатировать и М. Маклюен («Книгопечатание в этом смысле имеет много общего с кино. При чтении печатного текста читателю как бы отводится роль кинопроектора. Он движется по ряду напечатанных букв со скоростью, позволяющей ему воспринимать движение авторской мысли» ${ }^{8}$. Но в целом и кино, и, в особенности, телевидение продолжили извлекать из мозаичных структур прессы тот потенциал, который в них становится существенным.

\section{9. Средства коммуникации между культурой и цивилизацией.

Чтобы понять нарастание в культуре мозаичности, ущемляющей права тех повествовательных структур, в которых утверждается личностное, т.е. авторское начало, необходимо иметь представление о том, что еще в конце XIX века называли «психологией масс». До сих пор, пытаясь проследить историю коммуникации под углом зрения негативных последствий ее вторжения в культуру, мы ставили акцент на перманентном отрыве неподлинной коммуникации от подлинной, оставшейся в глубокой истории. Какие-то уровни этой неотчужденной коммуникации продолжают сохраняться и в современной культуре, хотя под них и подведен уже фундамент электронных технологий.

Но есть еще один аспект функционирования коммуникации, связанный, с одной стороны, с тем, что в свое время Г. Лебон называл «психологией масс», а позднее в науке будут называть социальной психологией, a, с другой, с обще-

\footnotetext{
7 Мандельштам О. Собрание сочинений в 4-х т., т. 2., М., 1991., с. 269;

${ }^{8}$ Маклюен М. Галактика Гутенберга. Сотворение человека печатной культуры. С. 187;
}

ственными структурами и государственными институтами. Ведь если допустить, что неподлинные средства на протяжении всей истории коммуникации распространяются, то это продиктовано силами и стихиями, находящимися не внутри, а вне коммуникативных процессов. Следовательно, эти процессы не всегда являются стихийными. Здесь возникает проблема направленности коммуникации. Касаясь воздействия интернета, Г. Рейнгольд пишет: «Нас заботит не только то, как мы пользуемся техникой, но и то, кем мы становимся, пользуясь ею» 9. Кого в данном случае Г. Рейнгольд имеет в виду под субъектом коммуникативных процессов? Личность, социальную группу, субкультуру, общество, государство?

До беспрецедентного взрыва, что имел место в коммуникативных процессах XX века, внешние силы в виде не только государства и церкви еще контролировали и сдерживали энергию масс, способную проявиться в разрушительных формах. Именно эту мысль и находит у Руссо Ж. Деррида, обращая внимание на констатируемое рассредоточение соседства, что, если перевести на специфическую для коммуникации терминологию, означает отсутствие интеракции в ее элементарной форме как выражение угнетения и произвола власти («Правительства, угнетающие свои народы, делают одно и то же: разрушают наличие и соналичие граждан, единодушие «собравшегося народа», рассеивают людей, держат своих подданных порознь, лишая их тем самым чувства сопринадлежности общему пространству речи и общения, основанного на убеждении» ${ }^{10}$.

Что же это означает, когда Ж. Деррида говорит о сопринадлежности каждого общему пространству речи? Это пространство и есть пространство площади или того типа коммуникации, которое успешно преодолевается в границах индустриальных и постиндустриальных обществ. Эта государственная политика введения участвующих в коммуникации масс в желаемое для государства русло сопровождает всю историю коммуникации. Поэтому коммуникация постоянно оказывается регулируемой. Следовательно, она постоянно склоняется к монологу, демонстрируемому тоталитарными обществами, а не диалогу.

О том, как это происходит, превосходно показывает Э. Каннети, прибегая к анализу

\footnotetext{
9 Рейнгольд Г. Умная толпа: новая социальная революция. М., 2006., с. 261;

${ }^{10}$ Деррида Ж. О грамматологии. М., 2000., с. 287;
} 
проявлений психологии массы в определенное время и в определенном пространстве. Правда, он это показывает, обращаясь к опыту церкви. Однако какие бы способы власть не применяла, чтобы масса изживала свои эмоции в границах рассредоточенной в пространстве коммуникации, тем не менее, в истории эти заданные и культивируемые государством коммуникативные нормы масса постоянно разрушала, возвращая к давно, казалось бы, преодоленным традиционным формам коммуникации, символизируемым площадью. Такими формами являются различные варианты поведения массы на улицах и площадях, когда масса нуждается в непосредственном выражении эмоционального напряжения, связано ли оно просто с праздничным временем или же с общественными потрясениями и необходимостью продемонстрировать власти свое недовольство. Архетипом такой формы коммуникации, пожалуй, можно считать Нагорную проповедь Христа.

Мы уже констатировали то, что в нашей науке существует традиция разведения средств коммуникации, в которых интеракция присутствует, и средств коммуникации, в которых она отсутствует. Мы уже отмечали, что те средства коммуникации, в которых интеракция предстает в своем непосредственном выражении, называются средствами массового воздействия, а те средства, в которых она лишь имитируется, а, по сути, отсутствует, называются средствами массовой коммуникации. Это обозначение, конечно, весьма спорное, поскольку средства массовой коммуникации представить без массового воздействия невозможно. Но сама попытка развести эти коммуникативные формы заслуживает внимания.

Чтобы понять комплекс массы, связанный со стремлением к неограниченному росту, обратимся к Э. Каннети, который как никто ощутил и попытался этот комплекс осмыслить. Э. Каннети фиксирует внимание на стремлении массы к своему росту до бесконечности. Однако этот комплекс массы культура постоянно ограничивала. К одному из способов такого ограничения прибегла церковь. «Благодаря равномерности служб, совершающихся в строго установленное время, - пишет Э. Каннети, - точности воспроизведения знакомых ритуалов массе обеспечивалась возможность как бы пережить самое себя в прирученном состоянии» ${ }^{11}$. Вот этому стремлению ограничивать выражение эмоций в своей непо-

\footnotetext{
${ }^{11}$ Каннети Э. Масса и власть. М., 1997., с. 25;
}

средственности в истории соответствовали не только культовые, но и зрелищные сооружения. В частности, античные амфитеатры, необходимость в которых ощущали императоры ${ }^{12}$. На примере функционирования таких амфитеатров можно проиллюстрировать, как человек трансформируется в человека массы или массового человека, ставшего позднее предметом внимания Х. Ортеги-и-Гассета.

Такие сдерживающие и ограничивающие средства были эффективными лишь до того периода радикальной переходности, что имела место в XX веке. Урбанизационные процессы, увеличение численности населения и рост городов как процессы, выражающие суть индустриальной цивилизации, привели к тому, что эффективно действующие в прошлой истории институты, регламентирующие поведение массы, с этими функциями больше не справляются. Масса испытывает желание ощутить свой рост и выйти за пределы навязываемых ей ограничений. Этот совершающийся переход закрытой массы в открытую Э. Каннети называет «извержением», что и составило смысл массовой коммуникации.

Как это «извержение» (Каннети) или «взрыв» (Маклюен) можно представить? Вот как описывает это извержение Э. Каннети. «Может быть потому, - пишет он, - что масса основательно очистилась от содержания традиционных религий, нам стало легче наблюдать ее в чистом, если угодно, биологически чистом виде, без тех трансцендентных смыслов и целей, которые раньше она позволяла в себя влить. История последних ста пятидесяти лет ознаменовалась резким увеличением числа извержений; это справедливо и по отношению к войнам, которые стали массовыми войнами. Масса уже не удовлетворяется благочестивыми обетами и обещаниями, она хочет испытать великое чувство собственной животной силы и страсти, используя для этого любые социальные претензии и поводы» ${ }^{13}$.

Понятно, что появление последующих технологий, на основе которых оказалось возможным развитие кинематографа, а затем телевидения и интернета явилось выходом из этого затруднительного положения. В данном случае как раз и важно поставить вопрос: а не происходит ли в случае появления каждого нового средства коммуникации разрыв между коммуникацией, с одной стороны, и культу-

\footnotetext{
${ }^{12}$ Хренов Н. Зрелища в эпоху восстания масс. М., 2006.

${ }^{13}$ Каннети Э. Указ. соч., с. 26;
} 
рой, с другой? История коммуникации обязана продемонстрировать процессы и разрыва, и, с другой стороны, преодоления такого разрыва. Чтобы этот вопрос прояснить, обратимся к тому направлению в изучении массовой коммуникации, которое называется археологией медиа. Это обращение позволит объяснить то, что со временем средство коммуникации, воспринимающееся первоначально как отклонение от культуры, тем не менее, со временем становится по отношению к ней репрезентативным.

Все дело в том, что возникающие средства коммуникации не всегда являются качественно новыми. В них проявляются существующие до предоставленных техникой возможностей культурные архетипы. В качестве иллюстрации действия архетипов обратимся к одному из направлений исторического изучения медиа, к идеям финского исследователя Э. Хухтамо. Хотя в этой концепции выявлены далеко не все аспекты расхождения между потенциальными возможностями медиа и способностями общества их освоить, тем не менее, в ней намечается приближение к актуальной теме исследования медиа. Она касается того, как история медиа соотносится с историей культуры, а также с историей тех форм, которые культура за тысячелетия своей истории успела сформировать. Сторонникам отождествления современной культуры с практикой медиа можно было бы в связи с этим предъявить такой аргумент. Несмотря на выпадение из культурной матрицы технологий, на основе которых функционируют медиа, все-таки культура не теряет надежды их вернуть в свою матрицу, окультуривать их и подчинять своей логике. Так, представляя сравнительно позднее изобретение, медиа, тем не менее, в своем функционировании нередко воспроизводят именно эти, подчас весьма архаические формы культуры, а не демонстрирует, как это часто кажется, нечто принципиально новое и культуре пока неизвестное.

Не случайно один из самых глубоких теоретиков медиа, в частности, кино и телевидения В. Михалкович находит аналогии между одержимостью в архаических и традиционных культурах временем и пространством и реализацией с помощью современных технологий этого комплекса в кино и телевидении. В связи с этим он обращает внимание на некоторые сюжеты Библии, в частности, на образ Аэндорской волшебницы, показывающей царю Саулу тень пророка Самуила. В этом сюжете улавливается идея волшебного фонаря как прообраза кино и телевидения. В библей- ском сюжете отсутствует деление времени на прошлое, настоящее и будущее. Комментируя этот архетип, В. Михалкович пишет: «Нечто аналогичное происходит благодаря кинематографу - он тоже отменяет тройственное членение времени: камера будто изымает фиксируемые объекты из его хода. В этом, полагал Андре Базен, кино будто смыкается с коллективным бессознательным, которому извечно присуща «потребность защитить себя от времени». Человек архаических культур ставил «посмертную жизнь в прямую зависимость от материальной сохранности тела». Отсюда возникла практика мумифицирования, направленная на то, чтобы «искусственно закрепить телесную видимость существа». Эту практику словно подхватили и продолжили технические средства репродуцирования: сначала фотография, которая «мумифицирует время, предохраняя его от самоуничтожения», затем - кино, благодаря которому «впервые изображения вещей становятся также изображением их существования во времени и как бы мумией происходящих с ними перемен». И кадр, и всякий фильм в целом сохраняют внутри себя основные, фундаментальные модальности времени - прошлое, настоящее и будущее, но частное, локальное время кадра или фильма отторжено от времени объективного мира и замкнуто в себе самом. Следует заметить, что такие же структуры локального, замкнутого времени присущи и телевидению, но сверх того ТВ будто гложет страсть к овладению все более масштабными пространствами, отчего все ощутимее углубляется расхождение между обоими средствами» ${ }^{14}$.

Теория Э. Хухтамо позволяет осмыслить медиа не только с точки зрения социологии, но и культурологии, хотя к обобщениям методологического характера сам Э. Хухтамо явно не склонен. Предпринявший исследование медиа в специфическом направлении Э. Хухтамо пишет: «В данном случае цель археологии медиа заключена в том, чтобы продемонстрировать, что за явлениями, которые на первый взгляд могут казаться беспрецедентными, часто скрываются модели и схемы, появившиеся в более ранних контекстах» ${ }^{15}$. Э. Хухтамо убежден, что, занимаясь раскоп-

\footnotetext{
14 Михалкович $B$. Кино и телевидение или о несходстве сходного. Киноведческие записки. 1996., № $30 .$, c. 97 ;

${ }^{15}$ Хухтамо Э. Элементы экранологии: к проблеме археологии медиа. В кн. : Экранная культура. Теоретические проблемы. СПб., 2012., с. 120;
} 
ками прошлого, археология медиа проливает свет на их настоящее. Так, сам Э. Хухтамо в истории зрелищной культуры пытается отыскать то, что применительно к кино и телевидению называют экраном. В ходе своих исследований он приходит к выводу, который является совершенно антимаклюеновским. Ссылаясь на Р. Уильямса, он пишет, что технология как таковая еще не определяет культурные формы, которые будут ей приданы ${ }^{16}$.

Сегодня эта проблема становится весьма актуальной в связи с функционированием интернета. Ведь его изобретатели явно не могли предусмотреть все возможные варианты его функционирования, т.е. того, как им способно воспользоваться общество. Пытавшийся понять последствия возникновения интернета на общество Г. Рейнгольд пишет: «ЭВМ и интернет закладывались их создателями, но то, как люди будут пользоваться ими, не закладывалось ни в какую технологию, и ни их создатели, ни продавцы не предвидели наиболее революционные приложения этих устройств» ${ }^{17}$. Таким образом, хотя Э. Хухтамо по поводу культуры и ее отношений с медиа и не философствует, тем не менее, он обнаруживает значимый аспект и исторической эволюции медиа, и тех противоречий в отношениях между медиа и культурой, которые в наше время достигают пика.

Они связаны с выявлением весьма непростых взаимоотношений между медиа и культурой, которые в некоторых суждениях предстают буквально синонимами, хотя на самом деле таковыми не являются. Разобраться в этом важно не только ради того, чтобы глубже понять природу, структуры и функции медиа, но и точнее представлять, что же такое культура как таковая, ее предназначение и ее функции. В отношениях коммуникации и культуры не просто разобраться, если в этот сюжет не ввести понятие цивилизации. Медиа связана с технологиями, а технологии выражают установку не только культуры, но и цивилизации. Там, где эти установки являются наиболее радикальными, ущемляются права культуры, т.е. гуманитарного ядра истории. Это означает, что коммуникация должна ориентироваться на личность или, если выражаться языком философии, на субъекта, точнее, на личность как субъекта.

Однако если коммуникацию рассматривать сквозь призму установок цивилизации, то

\footnotetext{
${ }^{16}$ Хухтамо Э. Указ. соч., с. 152;

${ }_{17}^{17}$ Рейнгольд Г. Указ. соч.. с. 256 ;
}

в этой коммуникации личность предстает уже не субъектом, а объектом. Ведь к личности цивилизация относится с функциональной точки зрения. Цивилизация делает человека функциональным, что порождает отчуждение. Общим контекстом социального функционирования медиа является история коммуникации, в которой постоянно ощущаются ее разрывы с культурой. Подчеркнем: конфликт между медиа и культурой есть частное проявление конфликта между культурой и цивилизацией. Медиа противостоит культуре тогда, когда реализует установки цивилизации, превращая человека в функциональное существо, объект, что свидетельствует о развертывающихся процессах отчуждения.

Конечно, когда О. Шпенглер обозначает последние столетия в истории культуры одной фазой и эту фазу он называет цивилизацией, он не так уж и не прав. Тем не менее, даже если не придерживаться точки зрения О. Шпенглера, очевидно, что в последние столетия цивилизация с ее политическими, экономическими и технологическими факторами, с ее ориентацией на материальные ценности, что привело к трансформации массовых обществ в общества потребления, теснит культуру, связываемую нами с духовными смыслами. Конечно же, функционирование медиа, развертывающееся на основе технологий, свидетельствует о медиа как, прежде всего, агенте цивилизации, а не культуры. Но отторгать медиа от культуры было бы ошибкой. Тем не менее, цивилизация исходит из человека, прежде всего, как объекта, относится к нему утилитарно и функционально. Между тем, человек есть субъект истории. История гуманитарных наук свидетельствует о сопротивлении нарастающему давлению цивилизации и, следовательно, отчуждения человека.

Такое сопротивление было реальным уже в ХУ111 веке, когда возникла эстетика как научная дисциплина, реабилитирующая принцип гедонизма. Построение Кантом эстетики свидетельствовало о возможности отвоевания у утилитарных сфер сферы свободы или игры. Для Канта и Шиллера игра и свобода, как известно, были синонимами. Успехи психологии, связанные с открытием бессознательного, также свидетельствовали о потенциале человеческого фактора. Возникшая в XIX веке социология пыталась разобраться в структуре индустриального общества. Это сопротивление утилитаризму как признаку цивилизации продолжается и на рубеже XX-XX1 веков. Но на этот раз такой сферой сопротивления 
цивилизации становятся не частные сферы вроде эстетики или психологии, а культура в целом. Вот почему в последние десятилетия в России такое значение придается культуре.

Цивилизация не способна преодолеть нарастающего отчуждения в обществе. Более того, именно она и оказывается определяющим источником такого отчуждения. На это претендует лишь культура. Вот ее возможности и следует познать. Осознавая эти возможности, мы открываем личностной потенциал коммуникации. Когда Й. Хейзинга пытается определить культуру, он утверждает: «только личность может быть тем сосудом, где хранится культура» ${ }^{18}$. И еще: «Культура рождается именно в личности, и соответственно имено в личности сохраняет свое здоровье» 19. Связывая коммуникацию с культурой, мы пытаемся, прежде всего, увидеть личность как субъекта коммуникативных процессов. Вместе с осознанием возможностей медиа следует осознать, в каком случае медиа является союзником культуры, а в каком она предстает ее антагонистом. Как мы пытались показать, медиа способна представать и в том, и в другом качестве, а решающим моментом в том, какую же, в конечном счете, роль она способна играть, являются общественные процессы. Культура стремится вернуть человека из объекта к субъекту. Поэтому ее цель связана с рассмотрением сферы игры, делающей человека свободным.

В том случае, когда медиа этому соответствует, ее постижение развертывается в контексте культуры. Но у медиа есть и другая сторона, которая культуре противостоит. То, что обычно называют развлечением как наравне с новостным и рекламным блоками (по крайней мере, это так сформулировано Н. Луманом) одним из значимых содержательных блоков функционирования медиа, как раз и представляет игровую стихию, расширяющуюся по мере возникновения каждого нового канала медиа и в особенности функционирующего на основе электронных технологий. В наше время развлечение расширилось до таких пределов, что, кажется, что в этой стихии утопает все, в том числе, и серьезное классическое искусство. Казалось бы, это в истории общества можно рассматривать величайшим прогрессом. Но вдумаемся в выводы Й. Хейзинги, констатирую-

${ }^{18}$ Хейзинга Й. Тени завтрашнего дня. Человек и культура. Затемненный мир. СПб., 2010., с. 177;

${ }^{19}$ Хейзинга Й. Указ. соч., с. 323; щего, что чем больше в XX веке появляется видов игры, чем шире становится игровая сфера, тем очевидней становится иссякание сущности игры, что свидетельствует уже об общей ситуации в культуре, а культуру Й. Хейзинга вообще связывает с игрой.

Таким образом, количественные показатели культуры, какими бы внушительными они не казались, далеко еще не свидетельствуют о ее качественных уровнях. Когда Й. Хейзинга говорит об исчезновении сущности игры, то причину этого следует усматривать в отношениях между культурой и цивилизацией. Сущность игры из культуры исчезает в том случае, когда культура активно ассимилирует то, что относится к цивилизации. Иначе говоря, выражаясь языком Ж. Дерриды, когда подлинное трансформируется в неподлинное. Видимо, эта ассимиляция цивилизации культурой, что приводит к угасанию игры, развертывается с помощью технологических революций, которые воспринимаются с такой эйфорией, но в реальности далеко не всегда являются позитивными. В результате этого проникновения в собственно культуру цивилизации уже не только под воздействием цивилизации, но и самой культуры в обществе развертывается отчуждение.

Это именно то, что в свое время Г. Зиммель пытался выявить в технике, науке, религии, праве, искусстве, а именно то, что делает человека не субъектом, а объектом. В результате такого давления цивилизации на культуру и проникновения продуктов и механизмов цивилизации в культуру, эта культура, по выражению Й. Хейзинги, «обременена таким грузом всяческого вздора и нелепых идей, какого никогда прежде не несла миру» ${ }^{20}$. Но раз человек трансформируется из субъекта в объект, не важно, происходит ли это под воздействием технологии, цивилизации или даже самой культуры, то мы как раз и можем констатировать отчуждение. В любом случае, в медиа, как в искусстве и культуре, позитивно лишь то, что способствует сохранению в человеке субъекта. Ведь в мире существует столько способов, чтобы этому не соответствовать.

В этой роли могут выступать не только государство, но, как это ни покажется парадоксальным, даже сама культура. И вот суждение Г. Зиммеля, свидетельствующее о том, что, несмотря на возникновение многих технологий, культура в XX веке оказалась в кризисе. Суть этого кризиса заключается в отклонении

${ }^{20}$ Хейзинга Й. Указ. соч., с. 174; 
технологического прогресса от человека как субъекта. «Вся гонка, ненасытность и жажда наслаждений нашего времени - лишь следствия и проявления реакции, вызванные тем, что личных ценностей ищут в той сфере, в которой их вообще не бывает: то, что успехи в технике прямо оцениваются как успехи в области культуры, что в области духа методы часто рассматриваются как нечто священное и считаются более важными, чем содержание и их результаты, что жажда денег значительно превосходит жажду вещей, способом приобретения которых они являются, - все это свидетельствует о постепенном вытеснении целей средствами и путями...» ${ }^{21}$. Вот это обстоятельство как раз и свидетельствует о том, что средства коммуникации в большей степени зависят от цивилизации, нежели от культуры. Но именно это обстоятельство и становится барьером для личности как субъекте коммуникативных процессов.

\section{0. Проблема идентичности личности сквозь призму реабилитации в постиндустриальном обществе традиционных средств коммуникации.}

Поскольку каждое новое средство коммуникации сопровождается конфликтом, то правомерно поставить вопрос: какой, в конечном счете, следует сделать вывод - или, наращивая коммуникативный потенциал и вызывая к жизни новые средства коммуникации, культура со временем разрешает все противоречия, снимая возникающие конфликты, или же она так и продолжает оставаться неспособной устранить травму, что возникает в связи с появлением каждого нового средства коммуникации, травму, которая оказывается уже антропологической травмой? В последнем случае происходит не снятие, а усиление первоначальной травмы, осознанной еще при появлении письменности Платоном. Ведь все следующие за письменностью средства коммуникации сохраняют отмеченное Платоном ее уязвимое место.

В любом случае, какими бы совершенными и даже фантастическими не были новые коммуникативные средства, адекватные глобализационным процессам, ностальгия по традиционным способам продолжает быть реальной. Появление каждого нового средства

${ }_{21}^{21}$ Зиммель Г. Кризис культуры. В кн. : Зиммель Г. Избранное., т. 1., Философия культуры. М., 1996., с. 491 коммуникации демонстрирует вовсе не взрыв, как это фиксируют Маклюен и Луман, а введение комплекса массы, связанного с потребностью в безграничном росте, в некую регулятивную матрицу, учреждаемую с помощью электронных технологий. В XX веке с помощью таких технологий человечество перешло на новый уровень коммуникации. Оно преодолело взрыв, связанный с омассовлением культуры и, кажется, разрешило многие противоречия в функционировании коммуникации. Однако, несмотря на насыщение социума различными каналами коммуникации, ему так и не удается забыть самую элементарную или, как выражается Леви-Строс, подлинную коммуникацию, которая предполагает выходящую на демонстрацию массу.

Комплекс площади продолжает оставаться по-прежнему притягательным и не случайно. В случае с площадью мы имеем в виду не только выражение истинной коммуникации, но и одну из форм социальности. Ведь именно на площади, на которой собирается масса, к человеку возвращается первичное чувство социальности. Толпа на площади и есть самая архаическая, самая древняя и самая элементарная форма социума, противостоящая перманентному нарастанию в культуре эффекта отчуждения человека от человека. Идеалом коммуникации для современного человека по-прежнему остается то, что постиг еще Руссо: прелесть общения в малых сообществах, где каждый знает каждого, где каждый знает только часть истины, а сама истина вовсе не появляется извне уже готовой, а возникает в процессе коммуникации или диалога. Собственно это будет утверждать и М. Бахтинлога. Эта истина сегодня, когда мир глобализируется, о чем свидетельствует распространение мировой паутины, открывается и постигается заново. Когда религия уже не является эффективным регулятивным средством, а идеология имперского типа с сопровождающим ее монологизмом также приказала долго жить, человечество может вернуться к тем кругам коммуникации, которые нередко ограничиваются локальными границами.

Иначе говоря, человечество стремится вернуть подлинное общение, возрождая традиционные ценности. Внимание к локальным и региональным способам коммуникации будет возрастать. Такое возрастание означает компенсацию исчезающих под воздействием глобализации традиционных средств коммуникации. Но ведь эта тенденция как раз в эпоху постиндустриального общества и явля- 
ется реальной. В качестве одной из обращающих на себя особенностей постиндустриального общества является, как свидетельствует Э. Тоффлер, выход за пределы массовидных образований, обязанных своим происхождением массовым коммуникациям и возвращение к реальным в контексте локальных культур традиционным способам коммуникации. Так, перечисляя признаки «третьей волны» или становления постиндустриального общества, Э. Тоффлер в качестве одного из таких признаков называет демассификацию медиа, т.е. ее возвращение к личности. «Вместо культурного доминирования нескольких средств массовой информации в цивилизации третьей волны - пишет он, - начнут преобладать интерактивные, демассифицированные средства, обеспечивающие максимальное разнообразие и даже персональные информационные запросы» ${ }^{22}$.

Так, опыт российских медиа в 1990-е годы, т.е. в период их ренессанса демонстрировал отход от массовых коммуникативных шаблонов в сторону индивидуализации контактов. Так, журналист из газеты «Коммерсант» А. Тимофеевский доказывает, что ориентация прежних изданий на определенные общности была перечеркнута. Газета «Коммерсант» обращалась не к общности, а к частному лицу («Его аудиторией стал отдельно взятый человек, частное лицо») ${ }^{23}$. Но соответствует ли такая ориентация на частное лицо природе медиа? Может быть, речь идет лишь об ориентациях какой-то одной субкультуры, а не общества в целом. Конечно, общие ориентации первоначально должны сформироваться в какой-то одной нише, в границах одной субкультуры, а затем уже транслироваться в массу. Но что-то не похоже, чтобы это в наше время уже происходило. Разве что этот процесс развертывается в формах интернета. В самом деле, кажется, что в связи с возникновением и распространением интернета эта тенденция продолжает укрепляться и развиваться.

Однако все эти связанные со становлением постиндустриального типа общества, а, следовательно, и с изменениями в структуре и функционировании медиа сдвиги своим следствием имеют и видоизменение идентичности. Новая эпоха формирует новый тип личности. Если же касаться медиа, то здесь в первую очередь следует иметь в виду то, что

\footnotetext{
${ }^{22}$ Тоффлер Э. Третья волна. М., 1999., с. 560;

${ }^{23}$ История русских медиа. 1989-2011., М., 2011., с. 26;
}

обычно называют мозаичными структурами. Что, собственно, радует и вместе с тем пугает в функционировании интернета? Это то, что является продолжением уже успевшего проявиться в телевидении, а еще ранее в газете, что бросалось в глаза и казалось разрушительным в XIX веке. Но бросалась в глаза именно эта мозаичность. Проблема мозаичности связана с утратой структур восприятии и мышления, сформированных книгопечатанием. Распространяясь, книгопечатание начало заметно воздействовать на культуру. По сути, именно изобретение Гутенберга подвело итог многовековому процессу отхода от анонимности автора. Несмотря на привнесенные в культуру противоречия, печатная книга стала мощным средством индивидуализации в культуре с эпохи Ренессанса.

В данном случае вопрос о взаимоотношениях между коммуникацией и культурой повернулся своей позитивной стороной. Ведь печатная книга, способствуя индивидуализации, стала, кроме всего прочего, мощным средством формирования и поддержания идентичности. Хотя идентичность для гуманитарной науки является новой проблемой, все же история медиа свидетельствует, что и до осознания актуальности этой проблемы, чему способствуют развертывающиеся процессы глобализации, медиа успешно формировали идентичность. В этом смысле весьма показательно такое средство медиа как печатная книга. Но в данном случае важно уяснить специфичность идентичности, формируемой с помощью печатной книги. Видимо, как можно предположить, эффект изобретения Гутенберга связан и с формированием особого образа человека. Не случайно Маклюен не обходит постановки вопроса, связанного со способностью печатного слова создавать особый тип человека. В связи с этим он обращает внимание на то, что Д. Джонс называет этот тип «алфавитно-мыслящим» ${ }^{24}$.

Однако очевидно, что уже спустя столетие под воздействием электронных технологий эта идентичность начала разрушаться и формироваться какая-то новая идентичность. Изобретение Гутенберга продолжало отрывать личность от различного рода человеческих сообществ. Этого вопроса коснулся Н. Луман, когда фиксировал расширение сферы развлечения как именно сферы медийной, в том числе, в литературных фор-

${ }^{24}$ Маклюен $M$. Понимание медиа: внешние расширения человека., с. 324 ; 
мax, начиная с XVIII века, т.е. века бурного развития романа. «Роман как художественная форма и выводимые из этого формы художественного вымысла, повествующие об увлекательном развлечении, - пишет Н. Луман, - рассчитаны на индивидов, которые уже не вводят свою идентичность из своего происхождения, но формируют ее сами. Соответствующая открытая, опирающаяся на «внутренние» ценности и гарантии социализация берет свое начало, предположительно, среди буржуазных слоев в XVIII столетии. Ныне она стала неизбежной. Всякий, едва родившись, обнаруживает себя в виде какого-то такого, кто еще только должен определить свою индивидуальность или позволить ей определиться по правилам некоей игры, «в которой ни он, ни кто-либо другой от начала времен не знает ни правил, ни рисков, ни ставок». Тогда будет весьма соблазнительно испробовать виртуальные реальности на себе самом, - по меньшей меpe, в воображении, которое можно остановить в любую минуту» ${ }^{25}$.

Собственно, Н. Луман затрагивает весьма значимую тему формирования и поддержания идентичности человека с помощью романа, который с эпохи раннего модерна переживает расцвет и тиражируется в беспрецедентных количествах. Так, вызванная к жизни ХУ111 веком страсть к чтению привела к тому, что с 1750 по 1800 годы число читателей удвоилось. За 10 лет с 1790 года по 1800 год на книжном рынке появилось 2500 новых романов, т.е. ровно столько, сколько их появилось за пятьдесят предыдущих лет. Для сравнения приведем такие цифры: в 1750 году вышло 28 новых романов, а в 1800-м уже 375 . К концу XVIII века около 25 \% населения можно было отнести к потенциально читающей публике ${ }^{26}$. Сравним эту статистику с тем, что представляла ситуация с функционированием книги в эпоху Гутенберга, печатавшего книги тиражом 150-200 экземпляров. Последователи его дела тиражи издаваемых книг довели до 250300 экземпляров ${ }^{27}$. В конце XV века тиражи поднялись уже до 1000 экземпляров.

Описывая ситуацию переходности от второй волны к третьей, т.е. от индустриального общества к постиндустриальному обществу, Э. Тоффлер обращает внимание на то обсто-

\footnotetext{
25 Луман Н. Реальность медиа., с. 96;

${ }^{26}$ Сафрански Р. Гофман. М., 2005., с. 48;

27 Функе Ф. Книговедение. Исторический обзор книжного дела., с. 55;
}

ятельство, что в этих процессах медиа тиражирует множество психологических типов, в том числе, «странных личностей, недоумков, чудаков и психов», чье антисоциальное поведение средства массовой коммуникации часто окружают романтическим ореолом. Наша критика давно уже использует для констатации этого явления термин «чернуха». Когда Э. Тоффлер пытается в этих отклоняющихся типах разобраться, он логично переходит к проблематике идентичности. «Тем временем миллионы людей - пишет он, - занимаются поисками своей идентичности или какого-то магического средства, которое помогло бы им вновь обрести свою личность, мгновенно дало бы ощущение близости или экстаза, привело бы их к более «высокому» состоянию сознания» ${ }^{28}$. Наблюдение Э. Тоффлера по поводу засилья типов с асоциальным поведением ассоциируется с методом деятельности репортеров газеты «Мегаполис-Экспресс», возникшей в период перестройки. Основатель газеты И. Дудинский признается, что журналисты из этой газеты искали убойные материалы в самых разных местах, в лежбищах бомжей, на свалках, бандитских притонах, моргах, кладбищах, венерических диспансерах, квартирах, населенных вельможами и колдунами ${ }^{29}$. Так в России рождалась бульварная пресса, способная, по признанию журналиста, «раскрепостить запуганного советской властью обывателя» ${ }^{30}$. Между прочим, в его признании есть и позитивный момент. Он признал: «В бульварной прессе я разглядел мощнейшее средство для воздействия на коллективное бессознательное» ${ }^{31}$. Это важно, однако, не только для бульварной, но и серьезной прессы. Однако из перечисленных антисоциальных типов новую идентичность не создать. Рано или поздно медиа в России оказывается перед необходимостью не только находить факты в тех местах и тех сферах, которые были при советской власти запретными, но и формировать новую идентичность, а здесь нужны были уже не только факты.

Из всех средств, наиболее эффективных в творчестве новых социальных ролей и идентификаций, у Э. Тоффлера первое место занимают функционирующие в новых условиях медиа. В границах «третьей волны» в выборе идентичности возникает большая

\footnotetext{
${ }_{28}^{8}$ Тоффлер Э. Указ. соч., с. 579;

${ }^{29}$ История русских медиа. 1989-2011..c. 126;

30 История русских медиа. с. 127;

${ }^{31}$ История русских медиа. с. 127;
} 
свобода. В контексте «второй волны» набор массово производимых образов ограничен («Относительно небольшое число издаваемых централизованно газет, журналов, радио-, телепередач и фильмов обеспечивали то, что критики назвали «монолитным сознанием». Индивиды постоянно соотносили себя с незначительным набором ролевых моделей и оценивали свой образ жизни, сравнивая его с несколькими предпочитаемыми возможностями. Круг социально одобряемых стилей поведения личности был относительно узок» ${ }^{32}$.

Иное дело- ситуация «третьей волны», когда имеет место демассификация средств массовой коммуникации, а, следовательно, и предлагаемое ими разнообразие моделей и стилей жизни. Они предполагают уже не ограниченный набор видов идентичности, а лишь мозаичные структуры. Свою идентичность потребитель медиа должен самостоятельно выстраивать из фрагментов этих предлагаемых медиа мозаик («Это гораздо труднее, и это объясняет, почему многие миллионы людей отчаянно ищут идентичность» 33. Поскольку этот процесс не закончился и, более того, под воздействием постмодерна набирает силу, то наше знание о формировании идентичности нового типа является неполным, открытым. Единственное, что здесь можно отметить, так это то, что наш новый опыт совершенно не похож на опыт предшествующих поколений, идентичность которых формировалась в границах индустриальных или массовых обществ. «Мир, в котором мы быстро вступаем, - пишет Э. Тоффлер, - настолько далек от нашего прошлого опыта, что все психологические гипотезы выглядят сомнительно. Однако абсолютно ясно, что мощные силы совместно воздействуют на изменение социального характера - развитие определенных черт, подавление других и, таким образом, изменение всех нас» 34 . Некоторые медиа ориентированы не только на то, чтобы претендовать на творение образа общества, но, скажем, на творение образа представителя какой-то социальной группы, скажем, группы успешных бизнесменов. Так, комментируя свой ролик, в котором был показан образ успешного бизнесмена, основатель газеты «Коммерсант» В. Яковлев признавался: «Это была первая попытка исполь-

\footnotetext{
${ }^{32}$ Тоффлер Э. Указ. соч.. с. 614;

33 тоффлер Э. Указ. соч., с. 614;

${ }^{34}$ Тоффлер Э. Указ. соч., с. 616;
}

зовать не реальный образ читателя, а то, кем он хотел бы себя видеть» 35 .

Иначе говоря, выражаясь языком Н. Лумана, в случае медиа мы имеем сконструированную реальность. Это в лучшем случае, поскольку мы пока, делая это заключение, исходим из интересов общества как самостоятельного по отношению к государству организма. Однако в отличие от общества, власти, контролирующей каналы медиа, также хочется в сознание людей внедрить тот образ государства, который ей кажется идеальным и совсем не означает, что он совпадает с этим образом, существующим в общественном сознании. Здесь возникает одна из самых серьезных проблем современности, связанная опять же с идентичностью человека. Она серьезна уже сама по себе, но поскольку, как утверждает Н. Луман, образ общества и мира формирует массмедиа, то они, как можно предположить, не могут не формировать и образ нас самих, т.е. нашу идентичность - и не только индивидуальную, но и коллективную.

Но если отдавать отчет в том, как в массмедиа конституируется реальность, то невозможно не поставить следующего вопроса: о чем в данном случае может идти речь - действительно ли об идентичности или о псевдоидентичности? Понятие «псевдоидентичность» употребляется Э. Эриксоном ${ }^{36}$. Эта проблема стала весьма острой в глобализирующемся мире, когда контакты между представителями разных культур стали более интенсивными, а часто они трансформировались в миграцию и иммиграцию. Несомненно, она является острой и для России. Но острой эта проблема стала еще на стадии перехода от доиндустриальных обществ к индустриальным. Именно эту причину возникновения идентичности как проблему выдвигает и Э. Әриксон - психолог, который, собственно, и вызвал к жизни целое направление в психологии, а именно, психологию и социологию идентичности, причем, связал ее с установками индустриального общества. «Промышленная революция, глобальная коммуникация, стандартизация, централизация и механизация угрожают идентичностям, унаследованным человеком от примитивных, аграрных, феодальных и аристократических культур - пишет он, - То, что внутреннее равновесие этих культур позволяло предложить, сейчас подвергается опасности в огромных масшта-

35 История русских медиа., с. 13;

${ }^{36}$ Эриксон Э. Детство и общество.СПб., 1996., с. 573; 
бах. Поскольку страх утратить идентичность доминирует в большей части нашей иррациональной мотивации, он призывает весь арсенал тревоги, оставленный в каждом человеке простым фактом его детства» ${ }^{37}$.

Таким образом, если уж искать исходную точку возникновения острых, связанных с медиа современных проблем, то в истории они возникают в момент перехода от обществ доиндустриальных к индустриальным обществам как значимой странице в истории, причем, в истории не только общества, но культуры и цивилизации. Вместе с реальностью индустриального общества в мир приходит функциональное отношение к человеку. Процесс отчуждения человека от общества и от своей самости с этого времени приближается к своим наиболее крайним формам. Видимо, это обстоятельство позволяет не только мыс- лить апологетическую историю бурного развития медиа, но в этой истории улавливать обострение развертывающихся процессов отчуждения уже в форме медиа. Если считать, что медиа - это сама культура в ее актуальных формах или хотя бы даже часть культуры, то для осмысления ее опыта, ее истории уместно прибегнуть к идее уже цитируемого нами Г. Зиммеля об отчуждении в самой культуре и в ее формах. В этом смысле медиа будет превосходной иллюстрацией этих процессов. Если рассматривать медиа в этой перспективе, то постмодернистскую трактовку идентичности как игры с собственными образами нередко приходится рассматривать именно как псевдоидентичности или симулякры. Единственным средством, позволяющим этого избегнуть, является исключающая симулякры культура.

\section{Список литературы:}

1. Автономова Н. Открытая структура: Якобсон, Бахтин, Лотман, Гаспаров. М., 2009;

2. Балаш Б. Культура кино. Л., 1925;

3. Буркхардт Я. Культура Италии в эпоху Возрождения. М., 1996;

4. Булгаков С. Два града. Исследования о природе общественных идеалов. СПб., 1997;

5. Вартанов А. Развитие киноязыка: от прямого эфира к интерактиву. В кн. : Средства массовой коммуникации в художественной культуре России XX века. , т. 3. Телевидение на рубеже веков (1980-2001 годы)., М., 2002;

6. Волков А. Об актуальных проблемах средств массового воздействия (СМВ) и средств массовых коммуникаций (СМК). В кн. : Предмет семиотики. Теоретические и практические проблемы взаимодействия средств массовых коммуникаций. М., 1975;

7. $\quad$ Гюго В. Собрание сочинений в 16 т., т. 2., М., 1953.;

8. Данилевский Н. Россия и Европа. Взгляд на культурные и политичесике отношения славянского мира к германо-романскому. М., 1991;

9. Деррида Ж. О грамматологии. М., 2000;

10. Зиммель Г. Кризис культуры. В кн. : Зиммель. Избранное., т. 1. Философия культуры. М., 1996;

11. История русских медиа. 1989-2011;

12. Каннети Э. Масса и власть. М., 1997;

13. Куренной В. Медиа: средства в поисках целей. Отечественные записки. 2003., № 4;

14. Леви-Строс К. Структурная антропология. М., 1983;

15. Луман Н. Реальность массмедиа. М., 2005;

16. Луман Н. Медиа коммуникации. М., 2005;

17. Мандельштам О. Собрание сочинений в 4-х т., т. 2., М., 1991;

18. Маклюен М. Понимание медиа: внешние расширения человека.М., 2003;

19. Маклюен М. Галактика Гуттенберга. Сотворение человека печатной культуры. Киев., 2003;

20. Михалкович В. Кино и телевидение или о несходстве сходного. Киноведческие записки. 1996., № 30;

21. Монтень М. Опыты. Книга 3., М., 1979;

22. Мотрошилова Н. Цивилизация и варварство в эпоху глобальных кризисов. М., 2010;

23. Моль А. Социодинамика культуры. М., 1973;

24. Ницше Ф. Воля к власти. Опыт переоценки всех ценностей. М., 2005;

37 Эриксон Э. Указ. соч., с. 572 
25. Платон. Сочинения в 3-х т., т. 2., 1970;

26. Рейнгольд Г. Умная толпа: новая социальная революция. М., 2006;

27. Розанов В. Уединенное. М., 1990;

28. Розанов В. Сумерки просвещения. М., 1990;

29. Сафрански Р. Гофман. М., 2005;

30. Стракович Ю. Музыкальная культура в цифровую эпоху. М., 2013;

31. Тарасов К. Насилие в зеркале аудиовизуальной культуры. М., 2005;

32. Тард Г. Публика и толпа. СПб;

33. Толстой Л. Собрание сочинений в 20 т., т. 18., М., 1965;

34. Токвиль де А. Демократия в Америке. М., 1992;

35. Тоффлер Э. Третья волна. М., 1999;

36. Третьяков С. Новый Лев Толстой. Новый Леф., 1927., № 1;

37. Функе Ф. Книговедение. Исторический обзор книжного дела. М., 1982;

38. Хейзинга Й. Тени завтрашнего дня. Человек и культура. Затемненный мир. СПб.,2010;

39. Хренов Н. Теоретические вопросы истории функционирования и развития массовой коммуникации. В кн. : В зеркале критики. Из истории изучения художественных возможностей массовой коммуникации. М., 1985;

40. Хренов Н. Зрелища в эпоху восстания масс. М., 2006;

41. Хренов Н. Социально-психологический аспект функционирования зрелищ в культуре города. В кн. : Театр как социологический феномен. СПб., 2004;

42. Хренов Н. К проблеме социологии и психологии кино 20-х годов. Вопросы киноискусства. M., 1976;

43. Хухтамо Э. Элементы экранологии: к проблеме археологии медиа. В кн. : Экранная культура. Теоретические проблемы. СПб., 2012;

44. Чуковский К. Собрание сочинений в 6 т., т. 6., М., 1969;

45. Шпенглер О. Закат Европы. Очерки морфологии мировой истории. М., 1993;

46. Эриксон Э. Детство и общество. СПб.,1996;

47. Ясперс К. Ницше. Введение в понимание его философствования. СПб., 2004

\section{References (transliteration):}

1. Avtonomova N. Otkrytaya struktura: Yakobson, Bakhtin, Lotman, Gasparov. M., 2009;

2. Balash B. Kul'tura kino. L., 1925;

3. $\quad$ Burkkhardt Ya. Kul'tura Italii v epokhu Vozrozhdeniya. M., 1996;

4. Bulgakov S. Dva grada. Issledovaniya o prirode obshchestvennykh idealov. SPb., 1997;

5. Vartanov A. Razvitie kinoyazyka: ot pryamogo efira k interaktivu. V kn. : Sredstva massovoi kommunikatsii v khudozhestvennoi kul'ture Rossii KhKh veka. , t. 3. Televidenie na rubezhe vekov (1980-2001 gody)., M., 2002;

6. Volkov A. Ob aktual'nykh problemakh sredstv massovogo vozdeistviya (SMV) i sredstv massovykh kommunikatsii (SMK). V kn. : Predmet semiotiki. Teoreticheskie i prakticheskie problemy vzaimodeistviya sredstv massovykh kommunikatsii. M., 1975;

7. $\quad$ Gyugo V. Sobranie sochinenii v 16 t., t. 2., M., 1953.;

8. Danilevskii N. Rossiya i Evropa. Vzglyad na kul'turnye i politichesike otnosheniya slavyanskogo mira k germano-romanskomu. M., 1991;

9. $\quad$ Derrida Zh. O grammatologii. M., 2000;

10. Zimmel' G. Krizis kul'tury. V kn. : Zimmel'. Izbrannoe., t. 1. Filosofiya kul'tury. M., 1996;

11. Istoriya russkikh media. 1989-2011;

12. Kanneti E. Massa i vlast'. M., 1997;

13. Kurennoi V. Media: sredstva v poiskakh tselei. Otechestvennye zapiski. 2003., № 4;

14. Levi-Stros K. Strukturnaya antropologiya. M., 1983;

15. Luman N. Real'nost' massmedia. M., 2005;

16. Luman N. Media kommunikatsii. M., 2005;

17. Mandel'shtam O. Sobranie sochinenii v 4-kh t., t. 2., M., 1991;

18. Maklyuen M. Ponimanie media: vneshnie rasshireniya cheloveka.M., 2003; 
19. Maklyuen M. Galaktika Guttenberga. Sotvorenie cheloveka pechatnoi kul'tury. Kiev., 2003;

20. Mikhalkovich V. Kino i televidenie ili o neskhodstve skhodnogo. Kinovedcheskie zapiski. 1996., № 30;

21. Monten' M. Opyty. Kniga 3., M., 1979;

22. Motroshilova N. Tsivilizatsiya i varvarstvo v epokhu global'nykh krizisov. M., 2010;

23. Mol' A. Sotsiodinamika kul'tury. M., 1973;

24. Nitsshe F. Volya k vlasti. Opyt pereotsenki vsekh tsennostei. M., 2005;

25. Platon. Sochineniya v 3-kh t., t. 2., 1970;

26. Reingol'd G. Umnaya tolpa: novaya sotsial'naya revolyutsiya. M., 2006;

27. Rozanov V. Uedinennoe. M., 1990;

28. Rozanov V. Sumerki prosveshcheniya. M., 1990;

29. Safranski R. Gofman. M., 2005;

30. Strakovich Yu. Muzykal'naya kul'tura v tsifrovuyu epokhu. M., 2013;

31. Tarasov K. Nasilie v zerkale audiovizual'noi kul'tury. M., 2005;

32. Tard G. Publika i tolpa. SPb;

33. Tolstoi L. Sobranie sochinenii v 20 t., t. 18., M., 1965;

34. Tokvil' de A. Demokratiya v Amerike. M., 1992;

35. Toffler E. Tret'ya volna. M., 1999;

36. Tret'yakov S. Novyi Lev Tolstoi. Novyi Lef., 1927., № 1;

37. Funke F. Knigovedenie. Istoricheskii obzor knizhnogo dela. M., 1982;

38. Kheizinga I. Teni zavtrashnego dnya. Chelovek i kul'tura. Zatemnennyi mir. SPb.,2010;

39. Khrenov N. Teoreticheskie voprosy istorii funktsionirovaniya i razvitiya massovoi kommunikatsii. V kn. : V zerkale kritiki. Iz istorii izucheniya khudozhestvennykh vozmozhnostei massovoi kommunikatsii. M., 1985;

40. Khrenov N. Zrelishcha v epokhu vosstaniya mass. M., 2006;

41. KhrenovN.Sotsial'no-psikhologicheskiiaspektfunktsionirovaniyazrelishchvkul'turegoroda.Vkn.: Teatr kak sotsiologicheskii fenomen. SPb., 2004;

42. Khrenov N. K probleme sotsiologii i psikhologii kino 20-kh godov. Voprosy kinoiskusstva. M., 1976;

43. Khukhtamo E. Elementy ekranologii: k probleme arkheologii media. V kn. : Ekrannaya kul'tura. Teoreticheskie problemy. SPb., 2012;

44. Chukovskii K. Sobranie sochinenii v 6 t., t. 6., M., 1969;

45. Shpengler O. Zakat Evropy. Ocherki morfologii mirovoi istorii. M., 1993;

46. Erikson E. Detstvo i obshchestvo. SPb.,1996;

47. Yaspers K. Nitsshe. Vvedenie v ponimanie ego filosofstvovaniya. SPb., 2004. 